\title{
Exceptionally low rotavirus incidence in the Netherlands in 2013/14 in the absence of rotavirus vaccination
}

S Hahné ${ }^{1}$, M Hooiveld ${ }^{1,2}$, H Vennema ${ }^{3}$, A van Ginkel ${ }^{1}$, H de Melker ${ }^{1}$, J Wallinga ${ }^{1}$, W van Pelt ${ }^{1}$, P Bruijning-Verhagen (p.bruijning@ umcutrecht.nl) ${ }^{1,4}$

1. Centre for Epidemiology and Surveillance (EPI), Centre for Infectious Diseases Control (CIb), National Institute for Public Health and the Environment (RIVM), the Netherlands

2. NIVEL (Netherlands institute for health services research), the Netherlands

3. Centre for Infectious Diseases Research, Diagnostics and Screening (IDS), Centre for Infectious Diseases Control (CIb), National Institute for Public Health and the Environment (RIVM), the Netherlands

4. Julius Center for Health Sciences and Primary Care, University Medical Centre Utrecht, the Netherlands

Citation style for this article:

Hahné S, Hooiveld M, Vennema H, van Ginkel A, de Melker H, Wallinga J, van Pelt W, Bruijning-Verhagen P. Exceptionally low rotavirus incidence in the Netherlands in 2013/14 in the absence of rotavirus vaccination. Euro Surveill. 2014;19(43): pii=20945. Available online: http://www.eurosurveillance.org/ViewArticle.

aspx?Articleld $=20945$

Article submitted on 13 October 2014 / published on 30 October 2014

An unexpected drop in rotavirus (RV) detections was observed in the Netherlands in 2014 , without RV vaccination. The estimated decrease in RV detections and gastroenteritis consultations in under five year-olds, in January-April 2014, compared to the same months in previous years, was $72 \%$ and $36 \%$, respectively. The low birth rate, mild winter, high RV incidence in the previous year and the introduction of $R V$ vaccination in neighbouring countries may have contributed to this decrease.

We describe an unexpected and large decrease in rotavirus (RV) detections in the Netherlands in the winter of 2013/14 compared to previous years. We corroborated this finding with our analysis of syndromic disease data on acute gastroenteritis (GE) in children under five years old, in which we also found a reduction and no sign of the usual peak in March. We believe that our findings are of great importance to the European public health community to alert other countries on the unusual RV epidemiology of the $2013 / 14$ winter.

\section{Background}

$\mathrm{RV}$ is a leading cause of GE in infants and young children. A number of European countries have recently implemented universal RV vaccination, including neighbours of the Netherlands (Belgium in 2006, UK (UK) and Germany in 2013) [1]. In the Netherlands, however, $R V$ vaccination is not part of the national vaccination programme and a national recommendation for its use has not been issued so far. On average, only 41 doses were distributed per year between 2011 and 2014 (personal communication, Truus Maessen, IP International Pharmacy GmbH, September 2014).

RV incidence in the Netherlands usually follows the typical seasonal pattern observed in temperate climates with an annual epidemic during winter months, peaking in February-March [2]. Up to 2014, RV was responsible for 3,300-4,800 hospitalisations annually in children underfive years old, of which $85 \%$ occurred between January and April with the highest incidence in those aged between six months and two years $[3,4]$.

Virological surveillance data showed an unexpected low number of RV detections in the Netherlands in the winter of $2013 / 14$. We studied this observation to assess whether it reflects a decreased circulation of RV and to discuss implications for the control of RV in the Netherlands and beyond.

\section{Epidemiological surveillance for rotavirus} infection, data collection and analysis

We studied RV laboratory detections from virological laboratory surveillance and all-cause GE consultations in under five year-olds from a Dutch sentinel General Practice (GP) network.

The virological surveillance collects weekly numbers of virus detections from between 17 and 21 virological laboratories registered with the Dutch Working Group for Clinical Virology (NWKV), serving primary care, hospitals and long-term care facilities. RV diagnostic testing is not routinely recommended for suspected infectious GE, but stool tests are performed in approximately two-thirds of children admitted for GE and in $10 \%$ of children with GE visiting primary care [3]. We analysed data from 1999 to 2014 by RV epidemiological year, defined as running from August to July of the following year.

We analysed GP consultations for allDcause GE in under five year-olds using routine electronic health record data from general practices participating in the NIVEL 


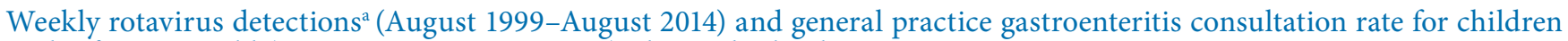
under five years old (August 2006-August 2014), the Netherlands

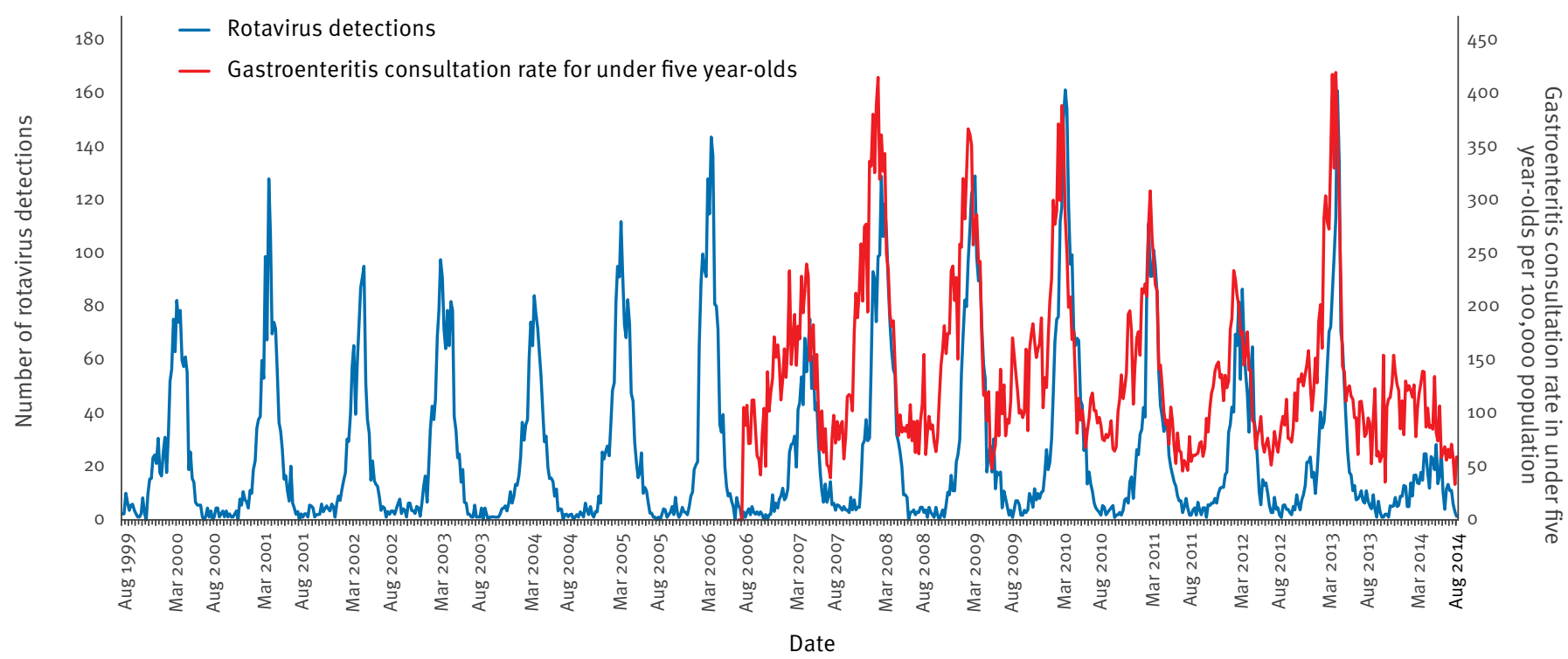

Adjusted for the weekly number of reporting laboratories by multiplying the number of rotavirus detections by the average number of reporting laboratories / the number of laboratories reporting that week.

Primary Care Database (NIVEL-PCD). Here, data were available from August 2006 to July 2014. Consultations are coded according to the International Classification of Primary Care (ICPC) [5]. Data are provided by 240 general practices covering a population of 1 million people, ca $5.5 \%$ of the Dutch population. Every Dutch citizen is obliged to be registered with a general practice. The GP acts as a gatekeeper for specialised, secondary healthcare. The electronic medical records kept by the GP, therefore, provide the most complete picture of the population's health.

Descriptive statistics were used to summarise data by RV epidemiological year and by seasonal month. Timeseries analysis was performed to assess trends in weekly counts of RV detections and in GE consultations in under five year-olds, and to compare the $2013 / 14$ RV season (January-April) to the same months in previous years. Negative binomial regression models were fitted to each data source separately. We adjusted the models for seasonal patterns (adding an indicator variable for month), for potential long-term linear trends and for variations in the number of reporting laboratories or person-time under observation, respectively. Both models were corrected for residual autocorrelation by adding lagged residuals.

\section{Results}

The weekly number of RV detections and the all-cause GE consultation rate in children under five year-old correlate well and were both much lower between August 2013 and August 2014 than in previous years (Figure).
Between August 1999 and July 2013, the average annual number of RV detections in virological surveillance, adjusted for the number of reporting virological laboratories, was 1,362 (range: 1,001-2,000). The adjusted number of RV detections between August 2013 and July 2014 was 570 (a 58\% drop). This RV epidemiological year registered by far the lowest number of RV detections in the entire time series. Reductions were most pronounced during February and March 2014 when the number of adjusted RV detections were down by $75 \%$ and $88 \%$, respectively. In contrast, an elevated number of RV detections was observed in July 2014 compared to previous years (Table). The peak in weekly RV detections in 2014 was shifted to May, whereas the peak was usually observed in March in previous years.

The mean weekly GE consultation rate in under five year-olds in the GP sentinel surveillance for the RV epidemiological years 2006-2013 was 152 per 100,000 person-weeks in under five year-olds (range: 111-201). The mean consultation for the $2013 / 14$ season was 97 per 100,000 (a $36 \%$ decrease). In accordance with RV laboratory detections, the decrease in GE consultations was most pronounced during February (55\%) and March (61\%) (Table). Furthermore, there was no sign of the usual peak in February-March in GE consultations.

In time-series analyses, both the model for RV detections and for the GE consultation rates confirmed significantly lower activity in the $2013 / 14$ season compared to previous years $(p<0.0001)$. The mean estimated decrease in RV detections for the 2014 winter season (January-April) compared to the same period in 
Weekly rotavirus detections and general practice gastroenteritis consultation rate by month, the Netherlands, $2013 / 14$ (August-July) compared to previous years

\begin{tabular}{|c|c|c|c|c|c|c|c|c|}
\hline \multirow{2}{*}{ Month } & \multicolumn{4}{|c|}{ Weekly mean number of RV detections ${ }^{a}$} & \multicolumn{4}{|c|}{$\begin{array}{l}\text { Weekly mean rate of GE consultations }{ }^{b} \\
\text { in children under five years old per } 100,000 \text { population }\end{array}$} \\
\hline & $\begin{array}{l}\text { Aug } 1999- \\
\text { Jul } 2013\end{array}$ & $\begin{array}{l}\text { Aug } 2013- \\
\text { Jul } 2014\end{array}$ & $\begin{array}{l}\text { Change in } \\
2013 / 14(\%)\end{array}$ & P-value ${ }^{c}$ & $\begin{array}{l}\text { Aug } 2006- \\
\text { Jul } 2013\end{array}$ & $\begin{array}{l}\text { Aug } 2013- \\
\text { Jul } 2014\end{array}$ & $\begin{array}{l}\text { Change in } \\
2013 / 14(\%)\end{array}$ & P-value ${ }^{c}$ \\
\hline Aug & 3.0 & $5 \cdot 3$ & +80 & 0.0910 & 90.6 & 69.4 & -23 & 0.0218 \\
\hline Sep & $3 \cdot 3$ & 5.4 & +63 & 0.3299 & 86.2 & 79.7 & -8 & 0.6515 \\
\hline Oct & 3.2 & 1.8 & -44 & 0.0626 & 89.7 & 83.3 & -7 & 0.8065 \\
\hline Nov & 5.0 & 3.7 & -26 & 0.2408 & 139.3 & 99.4 & -29 & 0.0703 \\
\hline Dec & 11.9 & 6.9 & -42 & 0.0046 & 171.4 & $135 \cdot 3$ & -21 & 0.0059 \\
\hline Jan & 25.7 & 8.8 & -66 & $<0.0001$ & 180.7 & 105.7 & -42 & 0.0001 \\
\hline Feb & 58.2 & 14.1 & -76 & $<0.0000$ & 269.8 & 122.3 & -55 & $<0.0001$ \\
\hline Mar & 85.2 & 15.0 & -82 & $<0.0001$ & 277.2 & 107.4 & -61 & $<0.0001$ \\
\hline Apr & 70.4 & 19.8 & -72 & $<0.0001$ & 205.4 & $117 \cdot 5$ & -43 & 0.0006 \\
\hline May & 31.3 & 21.4 & -32 & 0.0103 & 112.3 & 95.3 & -15 & 0.1996 \\
\hline Jun & 12.5 & $14 \cdot 3$ & +15 & 0.7158 & 95.3 & $75 \cdot 5$ & -21 & 0.1675 \\
\hline Jul & 5.1 & 11.7 & +131 & $<0.0001$ & 88.5 & 62.3 & -30 & 0.0001 \\
\hline
\end{tabular}

GE: gastroenteritis; RV: rotavirus.

The usual RV season (January-April) is highlighted.

a Adjusted for the weekly number of reporting laboratories by multiplying the number of rotavirus detections by the average number of reporting laboratories / the number of laboratories reporting that week.

b International Classification of Primary Care (ICPC) code D73.

Derived by performing t-tests.

2000-2013 was $72 \%$ (95\% Cl: 59-81\%). The estimated decrease in GE consultation rate for the 2013/14 winter season, which was adjusted for the presence of a significant linear time trend, was 36\% (95\% Cl: 17-50\%).

\section{Discussion}

We observed an exceptionally low number of RV detections and a low primary care GE consultation rate in children under five years of age, with nearly complete absence of winter excess, during the period of the typical RV season in 2014. This is a striking finding in the absence of RV vaccination in the Netherlands. The observation that the decrease was found in both datasets indicates that the low number of RV detections is not a surveillance artefact, and likely reflects reduced RV circulation. Our RV data did not include the number of RV tests performed. However, there have been no changes in diagnostic guidelines or reimbursement policy that could have impacted RV testing practices in 2014 compared to previous years.

Potential contributing mechanisms for the reduced RV circulation in 2013/14 include the mild winter, the relatively high RV epidemic season in the previous year, a low birth rate and, possibly, RV vaccination programmes in the neighbouring countries [6-8].

RV transmission can be affected by weather-related differences in human behaviour or virus survival. For the Netherlands, it has been estimated that for every degree Celsius rise in temperature above a threshold of
4 degrees the number of symptomatic RV infections in the Dutch population decreases by $9 \%$. Winter 2013/14 was unusually mild in the Netherlands: the average daily temperature was 2.6 degrees above the average of $3.4^{\circ} \mathrm{C}$, while four out of five preceding winters were considerably colder than the average [9]. This may have contributed to reduced RV transmission in 2013/14.

The recent history of the intensity of RV-seasons is a likely determinant of the future incidence, through depletion of susceptibles. In our RV time-series, this effect is not clearly discernible in the pattern of high and low epidemic peaks. Nevertheless, the relatively high incidence in $2012 / 13$ is likely to have contributed in this manner to the low incidence in 2013/14. The 2013 introduction of RV vaccination in the UK and Germany may also have contributed to a reduction of RV circulation in the Netherlands by reducing the number of introductions of RV into the Netherlands. In Germany, the RV vaccine has been used in some eastern federal states since 2006 , with evidence of local impact [10]. Notifications dropped by 36\% in 2014 compared to 2013 [11]. This suggests that coverage increased only moderately since the introduction of a national RV vaccine recommendation. Furthermore, we are unaware of reports of such effects in other countries bordering regions with universal infant RV vaccination and no decline in RV activity in the Netherlands was observed after Belgium introduced RV vaccination in 2006 with immediate high uptake. In France, a country without routine RV vaccination where between 
5 and $10 \%$ of infants are vaccinated each year in the private sector, the threshold for epidemic GE was, for the first time since 1992, not reached in the winter of 2013/14. This suggests that RV transmission was low in France also (personal communication, Daniel LévyBruhl, September 2014).

Mathematical modelling studies have suggested that recruitment of susceptible infants, as determined by birth rate and $R V$ vaccination coverage, is a main determinant in timing of RV season and in generating annual or biennial epidemics [6]. In the Netherlands, the birth rate has dropped to an all-time low of 10.2 per 1,000 population in 2013 [12]. This may now have reached a level at which timing of epidemics is shifted towards April-May and occur biennially, similar to the pattern observed in the United States, where recruitment of susceptibles is nowadays diminished due to the widespread use of RV vaccination.

Circulation of an unusual RV strain causing relatively mild disease could also result in lower numbers of RV related hospitalisations and GP visits. However, RV genotype surveillance for the 2013/14 season did not demonstrate an abnormal pattern of RV strains in the Netherlands. $\mathrm{G}_{1} \mathrm{P}[8]$ was the dominant strain until 2012. Since 2012 a varying mixture of $\mathrm{G}_{1} \mathrm{P}[8], \mathrm{G}_{2} \mathrm{P}[4]$, $\mathrm{G}_{3} \mathrm{P}[8], \mathrm{G}_{4} \mathrm{P}[8], \mathrm{G}_{9} \mathrm{P}[8]$, and $\mathrm{G}_{12} \mathrm{P}[8]$ has been observed (unpublished data).

\section{Conclusion}

The incidence of RV infections was exceptionally low in the Netherlands in the winter of 2013/14 in the absence of RV vaccination. This finding is relevant to countries assessing the impact of RV vaccination. Data from other European countries with and without RV vaccination and mathematical modelling are needed to provide further insight in determinants of low and high epidemic years. The risk of a compensatory hyperepidemic RV season in the coming year(s) needs to be urgently assessed, to allow adequate hospital bed capacity management and to inform RV vaccination policy [13].
References

1. Parez N, Giaquinto C, Du Roure C, Martinon-Torres F, Spoulou V, Van Damme P, et al. Rotavirus vaccination in Europe: drivers and barriers. Lancet Infect Dis. 2014;14:416-25. http://dx.doi. org/10.1016/S1473-3099(14)70035-0

2. Cook SM, Glass RI, LeBaron CW, Ho MS. Global seasonality of rotavirus infections. Bull World Health Organ. 1990;68:171-7.

3. Bruijning-Verhagen $P$, Sankatsing V, Kunst A, van der Born C, Bleeker E, Thijsen S, et al. Rotavirus-related hospitalizations are responsible for high seasonal peaks in all-cause pediatric hospitalizations. Pediatr Infect Dis J. 2012;31:e244-9.

4. Friesema IHM, De Boer RF, Duizer E, Kortbeek LM, Notermans DW, Smeulders A, et al. Etiology of acute gastroenteritis in children requiring hospitalization in the Netherlands. Eur J Clin Microbiol Infect Dis. 2012;31:405-15. http://dx.doi.org/10.1007/ s10096-011-1320-0

5. Hooiveld M, Donker GA, Schellevis FG. Netherlands institute for health services research (NIVEL). Primary Care Database- surveillance. Utrecht: NIVEL. [Accessed 26 Aug 2014]. Available from: http://www.nivel.nl/en/dossier/ nivel-primary-care-database

6. Pitzer VE, Viboud C, Simonsen L, Steiner C, Panozzo CA, Alonso WJ, et al. Demographic variability, vaccination, and the spatiotemporal dynamics of rotavirus epidemics. Science. 2009;325:290-4. http://dx.doi.org/10.1126/science.1172330

7. Pitzer VE, Viboud C, Lopman BA, Patel MM, Parashar UD, Grenfell BT. Influence of birth rates and transmission rates on the global seasonality of rotavirus incidence. J R Soc Interface. 2011;8:1584-93. http://dx.doi.org/10.1098/rsif.2011.0062

8. Atchison CJ, Tam CC, Hajat S, van Pelt W, Cowden JM, Lopman BA. Temperature-dependent transmission of rotavirus in Great Britain and The Netherlands. Proc Biol Sci. 2010;277:933-42. http://dx.doi.org/10.1098/rspb.2009.1755

9. Royal Netherlands Meteorological Institute (KNMI) Season overviews. [Accessed 25 Sep 2014]. Dutch. Available from: http://www.knmi.nl/klimatologie/ maand_en_seizoensoverzichten/\#seizoen

10. Uhlig U, Kostev K, Schuste V, Koletzko S, Uhlig H. Impact of Rotavirus Vaccination in Germany: Rotavirus Surveillance, Hospitalization, Side Effects and Comparison of Vaccines. Pediatr Infect Dis J. 2014 Jun 6. [Epub ahead of print].

11. Robert Koch Institute (RKI). Aktuelle Statistik meldepflichtiger Infektionskrankheiten, Deutschland. [Current statistics on notifiable infectious diseases, Germany]. Epidemiologisch Bulletin 2014:37:370. 15 Sep 2014. German. Available from: https://www.rki.de/DE/Content/Infekt/EpidBull/Archiv/2014/ Ausgaben/37 14.pdf? blob=publicationFile

12. Centraal Bureau voor de Statistiek (CBS). [Statistics Netherlands]. Statline. Birth rate by year. Den Haag/ Heerlen: 6 Aug 2014. Dutch. Available from: http://statline. cbs.nl/Statweb/publication/?DM=SLNL\&PA=37422ned $\& D_{1}=1,4-5,7,9,11,13,17,26,35,40-41 \& D_{2}=0,10,20,30,40,59$ $63 \& H D R=G 1 \& S T B=T \& V W=T$.

13. Bruijning-Verhagen $P$, Mangen $M-J$, Felderhof $M$, Hartwig NG, van Houten $M$, Winkel $L$, et al. Targeted rotavirus vaccination of high-risk infants; a low cost and highly cost-effective alternative to universal vaccination. BMC Med. 2013;11:112. http://dx.doi.org/10.1186/1741-7015-11-112

\section{Acknowledgements}

We would like to thank laboratories, the Dutch Working Group for Clinical Virology (NWKV) and GPs contributing to virological and primary care surveillance.

Conflict of interest

None declared.

\section{Authors' contributions}

Designed the study: SH, PB-V, WvP. Collected, synthesised and analysed data: SH, PB-V, MH, AvG. Wrote the first draft: $\mathrm{SH}, \mathrm{PB}-\mathrm{V}$. Interpreted the results and revised the article: $\mathrm{SH}$, MH, PB-V, JW, AvG, WvP, HV, HdM. All authors read and approved the final manuscript. 